\title{
Reciclagem e sustentabilidade ambiental: a importância dos processos logísticos
}

\author{
João Carlos Souza ${ }^{1}$
}

\begin{abstract}
Resumo: Cresce a consciência que os recursos do planeta são finitos e, caso não se tomem providências para o controle da poluição e do aquecimento global, é possível que em longo prazo a vida na terra se torne inviável. Em função deste fato, surge nos meios acadêmicos um grande interesse em torno da "Logística para Reciclagem", que pode ser definida como o processo de planejamento, implementação e controle da eficiência e eficácia e dos custos, dos fluxos de matérias-primas, produtos em estoque, produtos acabados e informação relacionada, desde o ponto de consumo até um ponto de reprocessamento, com o objetivo de recapturar valor ou realizar a deposição adequada. O modelo proposto neste trabalho tem por objetivo destacar a importância dos processos logísticos para que as atividades de reciclagem de materiais sejam eficientes e ajudem a garantir a sustentabilidade ambiental. Foi feita uma aplicação simulada para a região de Florianópolis e municípios adjacentes.

Palavras-chave: reciclagem; sustentabilidade ambiental; processos logísticos.
\end{abstract}

\begin{abstract}
The awareness about the finiteness of the resources of our planet is growing up, and life on earth might be unviable, if the right measures are not taken to control pollution and global warming. Due to this fact, interest on "Recycling Logistics" has been growing. Recycling Logistics, as well as reverse logistics, is traditionally defined as the process of planning, implementing, and controlling the efficient, cost-effective flow of raw materials, in-process inventory, finished goods and related information from the point of consumption to an reprocessing point for the purpose of recapturing value or proper disposal. The model proposed in this paper was applied in the region of Florianópolis and adjacent municipalities and aims to highlight the logistics for the activities of materials recycling and their importance to environmental sustainability.

Keywords: recycling; environmental sustainability; logistic processes
\end{abstract}

\section{INTRODUÇÃO}

A grande maioria dos produtos e materiais utilizados pela humanidade não é totalmente consumida, restando uma significativa parcela de resíduos. Estes resíduos poderão seguir três destinos diferentes: $(a)$ serem sendo lançados diretamente na natureza, poluindo o ambiente, ou, $(b)$ irem para um local de descarte seguro, como aterros sanitários e depósitos específicos; (c) submeterem-se a um processo de reclicagem, com reprocessamento e devolução ao mercado dos produtos antes descartados.

Como o volume de lixo tem aumentado numa taxa superior ao crescimento da população, a maioria dos aterros sanitários, mesmo os que foram corretamente projetados e corretamente construídos e utilizados, já está com sua capacidade próxima do limite. Para evitar a completa saturação, têm sido envidados esforços no sentido de reintegrar pelo menos alguns dos resíduos nos processos produtivos originais ou em processos produtivos alternativos. Esta reintegração de determinados produtos pode levar a um desenvolvimento econômico e populacional um pouco mais sustentável, reduzindo em parte o risco de contaminação do meio ambiente, com sérias consequências para as futuras gerações.

Pode-se definir o processo de reciclagem como um conjunto de técnicas que tem por finalidade aproveitar os "detritos" e reutilizá-los no ciclo de produção de que saíram ou em um ciclo de produção paralelo. A reciclagem é uma ati-

\footnotetext{
${ }^{1}$ João Carlos Souza, Programa de Pós Graduação em Arquitetura e Urbanismo, Departamento de Arquitetura e Urbanismo, Universidade Federal de Santa Catarina, Florianópolis, SC, Brasil. (e-mail: jcsouza@arq.ufsc.br).

Manuscrito recebido em 2/6/2010 e aprovado para publicação em 5/3/2011. Este artigo é parte de TRANSPORTES v.19, n.1, 2011. ISSN: 2237-1346 (online).
}

vidade pela qual, materiais que poderiam se tornar lixo, ou que já estão no lixo, são desviados, coletados, separados e processados para serem usados como matéria-prima na manufatura de novos produtos. Como, para as empresas reclicadoras, estas matérias recuperadas sempre têm um custo mais conveniente que o da matéria prima original, caso contrário elas se negariam a utilizá-los, cabe à logística viabilizar economicamente o transporte e a armazenagem dos produtos, obtendo, como efeito colateral benéfico, uma diminuição dos danos ao meio ambiente.

Fica evidenciada a importância da logística no processo de reintegração na cadeia de abastecimento dos resíduos recuperados, no entanto, isto implicará num fluxo adicional de materiais e de informações, em sentido inverso ao tradicional. A cadeia de abastecimento resultará em um circuito fechado, que terá de englobar não só as atividades logísticas tradicionais, de abastecimento, produção, distribuição e consumo como, também, as atividades associadas à logística inversa, aqui também entendida como a logística para reciclagem, com a função de recolhimento, inspeção, separação, reprocessamento, deposição e redistribuição de resíduos recuperados.

\section{OBJETIVO}

O objetivo desta pesquisa foi ressaltar a importância das diversas atividades da logística: transporte, gestão de estoques e processamento de informações, para apoio às atividades que contribuem para a sustentabilidade ambiental através da reciclagem de materiais. Não será feita uma profunda revisão teórica sobre os processos logísticos, pois são assuntos muito bem discutidos na literatura disponível.

Para validação do estudo, analisaram-se os processos logísticos que são envolvidos para a coleta e posterior reciclagem de papéis, metais, plásticos e vidros, na região co- 
nurbada de Florianópolis, SC, e municípios vizinhos. Foram utilizadas ferramentas da pesquisa operacional para otimizar a localização dos postos de coleta dos resíduos, modelos de simulação para prever a oferta de materiais recicláveis em cada um dos distritos em que foi dividida a área de estudo e modelos da teoria das filas para estimar a frequência média de despacho dos caminhões carregados com sucata, simulação para prever a oferta de itens recicláveis.

Uma questão interessante que surge é por que somente alguns produtos despertam interesse nas indústrias para serem reciclados, enquanto que outros, mesmo tendo algum valor residual, simplesmente são rejeitados? A resposta é: As indústrias consideram a reciclagem como mais uma fonte de matéria prima pra seus processos produtivos e, em função disto, aplicam os mesmos princípios da Economia, ou seja, procuram o menor preço dos insumos de modo a obter o maior lucro possível. Então, somente incluem produtos reciclados no seu ciclo de produção se estes tiverem um custo menor que o de sua matéria prima convencional.

\section{LOGÍSTICA E LOGÍSTICA PARA RECICLAGEM}

A clássica função da logística seria gerenciar o fluxo de informações, a movimentação e a armazenagem temporária de materiais, desde o ponto de aquisição da matéria prima até o ponto de consumo dos produtos acabados. No entanto, para uma grande gama de materiais e produtos, existe também o fluxo reverso, desde o ponto de consumo até um ponto de origem ou próximo dele. Este fluxo reverso igualmente necessita ser gerenciado.

De modo mais formal, o "Council of Logistics Management" (CLM, 1993), define logística como o "processo de planejamento, implementação e controle da eficiência e eficácia e dos custos, dos fluxos de matérias-primas, produtos em estoque, produtos acabados e informação relacionada, desde o ponto de origem até o ponto de consumo, com o objetivo de atender as necessidades dos clientes". Rogers e Tibben-Lembke (1998) completam a definição adaptando-a para a logística reversa. Segundo estes autores, o conceito de logística reversa inclui todas as atividades acima mencionadas considerando, porém, que as atividades são operadas em sentido oposto: "O processo de planejamento, implementação e controle da eficiência e eficácia e dos custos, dos fluxos de matérias-primas, produtos em estoque, produtos acabados e informação relacionada, desde o ponto de consumo até o ponto de origem, com o objetivo de recapturar valor ou realizar a deposição adequada".

A logística para reciclagem, embora semelhante, não pode ser confundida com a logística reversa, pois esta última refere-se ao retorno do produto ao seu ponto de origem, enquanto que a primeira não tem esta obrigatoriedade. Através da logística para reciclagem, o produto também percorre um fluxo inverso, no entanto não necessita retornar para o seu ponto de fabricação original, pode tomar qualquer destino, podendo ser direcionado para sistemas de processamento completamente diferentes daqueles que lhe deram origem. Por exemplo, as garrafas PET nunca retornam às indústrias de bebidas para serem preenchidas novamente. Quando recuperadas, após o consumo do líquido, elas seguem para servir como matéria prima para tecidos, cordas e outros fins.

Desde a primeira definição da logística reversa elaborada em 1993 pelo "Council of Logistics Management" (CLM), varias evoluções se sucederam a este conceito inicial. Stock, Roger e Tibben-Lembke, Dornier et al.; Bowersox e Closs apud Leite (2003) contribuíram conceitualmente para o processo de evolução desta definição, que encontra ainda novas possibilidades de alteração em função do crescente interesse empresarial e de pesquisa nesta área.

"Entendemos a logística reversa como a área da logística empresarial que planeja, opera e controla o fluxo e as informações logísticas correspondentes, do retorno dos bens de pós-venda e pós-consumo ao ciclo de negocio ou ao ciclo produtivo, por meio de canais de distribuição reversos agregando-lhes valor de diversas naturezas: econômico, ecológico, legal, logístico, de imagem corporativa, entre outros" (Leite, 2003).

Alguns canais logísticos reversos já são comuns em muitas empresas. Por exemplo, fabricantes de bebidas gerenciam todo o retorno das garrafas dos pontos de venda até seus centros de distribuição. As siderúrgicas usam como insumo de produção em grande parte a sucata gerada por seus clientes e para isso usam centros coletores de carga. Existem ainda outros setores da indústria onde o processo de gerenciamento dos canais de suprimento reversos é mais recente como na indústria de eletrônicos, automobilística e de produtos radioativos.

Um exemplo clássico de logística para reciclagem de materiais é o caso das latas de alumínio e das garrafas plásticas, recuperando-se mais de $70 \%$ destas embalagens. No entanto, nem a indústria que produz as latas ou as garrafas, nem a indústria engarrafadora, se envolvem com o processo de recolhimento ou recuperação. Os catadores entregam as latas e as garrafas para intermediários que fazem a compactação destes produtos e repassam para um nível superior de atravessadores.

Como já comentado anteriormente, as garrafas plásticas não podem ser aproveitadas novamente na indústria de embalagens, mas têm uma demanda muito grande para outros usos. Já o alumínio das latas pode ser novamente transformado em latas ou, evidentemente, em diversos outros produtos. Como já comentado anteriormente, deve-se ressaltar que a indústria só recompra a lata porque esta é uma matéria prima muito mais barata do que o alumínio oriundo da bauxita. Isto é a mesma coisa que acontece com qualquer outra indústria que usa produtos reciclados, como papel, ferro, plástico, entre outras. Somente adquirem aqueles produtos se eles tiverem um custo menor que o de sua matéria prima convencional.

\section{LOCALIZAÇÃO DE CENTROS DE COLETA EM ÁREAS URBANAS}

Sistemas de coleta de materiais recicláveis em centros urbanos são imprescindíveis para o bom funcionamento das cidades. Torna-se necessário que sejam bem estudados e racionalizados. Para tanto, podem ser usados os modelos da Pesquisa Operacional, que permitem inferir a solução ótima que maximize a eficiência daqueles sistemas. Um ponto fundamental a considerar no dimensionamento de modelos de coleta ou de distribuição de mercadorias é o critério de avaliação ou, na linguagem de Pesquisa Operacional, a função objetivo do problema. Essa função objetivo, em princípio, deve visar primordialmente a minimização de custos.

Neste trabalho foram propostos critérios práticos para 
distribuir centros de coleta de resíduos utilizáveis numa área urbana. Utilizou-se, além do critério da distância entre os diversos distritos ou bairros, informações relativas à oferta de produtos em cada um destes distritos. Criou-se um "índice de oferta" para ponderar o valor das distâncias entre cada zona, ou seja, os distritos com maior população e com maior oferta são privilegiados na distribuição espacial dos centros de coleta - CCs.

Adotou-se o clássico modelo $p$-mediana, onde o número $p$ de CCs é um dado exógeno, ou seja, pré-estabelecido, procurando-se distribuí-los de modo que o maior número de coletadores tenha acesso ao serviço de entrega, dentro de uma distância máxima estabelecida, procura-se minimizar a soma dos custos de transportes associados com os veículos alocados nos $p$ CDs.

O problema pode matematicamente ser expresso como:

$$
\operatorname{Minimizar} Z=\min \left(\sum_{j=1}^{n} \sum_{i=1}^{m} d_{i j} x_{i j} a_{i}\right)
$$

em que,

$x_{i j}$ : 1 se a facilidade no local $j$ atende a zona $i, 0$ nos outros casos;

$d_{i j}$ : o "custo" para que o $\mathrm{CC} j$ atenda a zona $i$; na aplicação do modelo considerou-se como o custo a ser minimizado a distância em quilômetros percorrida pelos coletadores, ou seja, quanto menos deslocamentos menor despesa com transporte terá o coletador;

$a_{i}$ : fator de ponderação do custo para atender o distrito $i$. Este fator é proporcional à demanda de coletadores, assim, os distritos com maior produção de material reciclável terão prioridade no atendimento; considerou-se como fator de proporcionalidade o "índice de oferta", que é a relação entre a quantidade de resíduos recicláveis produzidos a área de cada distrito;

$n$ : número se distritos; e

$m$ : número de distritos aptos a receberem os CCc; normalmente $m=n$.

Sujeito a:

$$
\sum_{j=1}^{n} y_{j}=p
$$

sendo,

$y_{j}$ : distrito onde está instalada a facilidade

Significa que o número $p$ de unidades a serem localizadas é pré-fixado, o que pode ser considerado como uma simplificação. O ideal é fazer uma ligação explicita entre o número de facilidades e os custos decorrentes do transporte e armazenagem das mercadorias. $\mathrm{Na}$ aplicação do modelo, o número de CC foi sendo ampliado sucessivamente, até que a distância média percorrida pelos coletadores não ultrapassasse um valor pré-estabelecido de $10 \mathrm{~km}$.

$$
\sum_{j=1}^{n} x_{i j}=1 \quad i=1,2, \ldots, m ;
$$

Garante que todos os distritos terão disponível um CC para armazenagem dos produtos recicláveis que sejam recolhidos;

$$
y_{j}>x_{i j} \quad i=1,2, \ldots, m ; \quad j=1,2, \ldots, n ;
$$

Assegura que a zona $i$ pode ser servida apenas por centros de coleta estabelecidos, isto é, se $x_{i j}=1$ então $y_{j}$ também deve ser igual a 1 .

$$
y_{j}, x_{i j} \in(0,1) \quad i=1,2, \ldots, m ; j=1,2, \ldots, n ;
$$

Como, no modelo de p-mediana, o número $p$ de unidades a serem localizadas é pré-fixado, isto pode ser considerado como uma simplificação. O ideal é fazer uma ligação explicita entre o número de facilidades e os custos decorrentes do transporte e armazenagem das mercadorias. Na aplicação do modelo, o número de CC foi sendo ampliado sucessivamente, até que a distância média percorrida pelos coletadores não ultrapassasse um valor pré-estabelecido de $10 \mathrm{~km}$. Garante que todos os distritos terão disponíveis um CC para armazenagem dos produtos recicláveis que sejam recolhidos, num raio máximo de $10 \mathrm{~km}$.

Por simplificação, para avaliar o intervalo de tempo em que veículos de maior capacidade deverão comparecer aos CC para carregar as mercadorias estocadas e transportá-las para as indústrias recicladoras, utilizou-se o modelo da teoria das filas:

- Considerou-se que os veículos cheguem ao depósito conforme uma distribuição de Poisson com média $\lambda$;

- Os tempos de atendimento, representados pela capacidade dos coletadores abastecerem os $\mathrm{CC}$, seguem a distribuição exponencial negativa com média $1 / \mu$;

- O atendimento da fila é feito por ordem de chegada;

- O número de clientes, representados pelos veículos, é suficientemente grande para que a população possa ser considerada infinita;

- A probabilidade de uma chegada é proporcional a $\Delta \mathrm{t}$, ou seja, igual a $\lambda . \Delta \mathrm{t}$;

- A probabilidade de término de um carregamento é proporcional ao intervalo de tempo $\Delta \mathrm{t}: \mu . \Delta \mathrm{t}$;

- A probabilidade de mais de uma chegada no intervalo $\Delta \mathrm{t}$ é desprezível. Logo, em $\Delta \mathrm{t}$ só podemos ter a chegada de um veículo, com probabilidade $\lambda . \Delta \mathrm{t}$, ou nenhuma chegada, com probabilidade $1-\lambda . \Delta \mathrm{t}$; e

- Propriedade análoga para o término do serviço: ou um veículo é carregado, com probabilidade $\mathrm{m} . \Delta \mathrm{t}$, ou nenhum, com probabilidade $1-\mu . \Delta \mathrm{t}$.

Para ajustar a distribuição real numa distribuição de Poisson calcula-se inicialmente a média $\bar{n}$ através dos dados observados, onde:

$$
\bar{n}=\frac{\sum_{n=0}^{\infty} n \cdot f_{n}}{\sum_{n=0}^{\infty} f_{n}}
$$

em que,

$n$ : número de observações; $\mathrm{e}$

$f_{n}$ : frequência observada.

A distribuição de Poisson é dada pela seguinte equação:

$$
P_{n}=\frac{\lambda^{n} e^{-\bar{n}}}{n !}
$$

O tempo médio gasto pelo veículo de transporte no sistema de fila é dado por:

$$
T=\frac{L}{\lambda}=\frac{1}{\mu-\lambda}
$$

e o tempo de espera na fila

$$
T_{q}=\frac{\lambda}{\mu(\mu-\lambda)}
$$


Tabela 1. Resultado da simulação para estimar a quantidade de material reciclável coletado em cada distrito (resumido)

\begin{tabular}{lccc}
\hline Distritos & $\begin{array}{l}\text { Coleta média anual } \\
(\boldsymbol{t})\end{array}$ & $\begin{array}{l}\text { Coleta média mensal } \\
(\boldsymbol{t})\end{array}$ & $\begin{array}{l}\text { População } \\
(\text { hab })\end{array}$ \\
\hline Centro/Norte & 1750 & 145,83 & 25000 \\
Centro/Sul & 1703 & 141,92 & 25536 \\
Estreito & 1413 & 117,75 & 22004 \\
Trindade/Carvoeira & 856 & 71,33 & 19048 \\
Capoeiras/V.São João & 641 & 53,42 & 14871 \\
Barreiros & 577 & 48,08 & 13600 \\
Coqueiros & 610 & 50,83 & 14500 \\
Passa Vinte & 461 & 38,42 & 11000 \\
Ipiranga/ Bela Vista & 446 & 37,17 & 11200 \\
Canasvieiras & 467 & 38,92 & 11500 \\
Agronômica & 437 & 36,42 & 11574 \\
Serraria & 423 & 35,25 & 11290 \\
\hline
\end{tabular}

\section{APLICAÇÃO PRÁTICA}

Como exemplo de aplicação prática deste trabalho utilizouse a otimização das atividades de uma empresa fictícia especializada na coleta de produtos recicláveis, na região conurbada da Grande Florianópolis, na qual se incluem também as áreas urbanas dos municípios de São José, Palhoça, Biguaçú e Santo Amaro da Imperatriz.

$\mathrm{Na}$ falta de dados reais prontamente disponíveis, para a implementação dos modelos matemáticos foi desenvolvido um processo de simulação para gerar uma possível distribuição da oferta na região de estudo, para que o modelo se aproximasse o máximo possível de uma situação real, foi usado como base informações de uma empresa que já trabalha com coleta de mercadorias recicláveis na Grande Florianópolis.

A produção de materiais recicláveis na região de Florianópolis varia muito conforme a época do ano, sendo intensificada nos meses de verão devido ao intenso afluxo de turistas à cidade. A empresa que se tomou como base para se estimar os volumes de materiais coletados para sofrerem reciclagem tem sua base operacional no bairro de Roçado e envia em média um caminhão com 15 toneladas de sucatas para São Paulo por mês. Considerando a população do bairro e o volume enviado para as indústrias recicladoras mensalmente, fez-se uma extrapolação para os demais bairros relacionando volume de resíduos produzidos com a população de cada um dos respectivos bairros, obtendo-se a média mensal de produtos recicláveis recolhidos em cada um deles.

Para obter-se um efeito mais real da oscilação da oferta, elaborou-se um modelo simples de simulação, no qual se tomou como base o volume médio inferido pela empresa piloto, a época do ano, o dia da semana e a oscilação diária da temperatura. Sabe-se que são produzidos mais resíduos nos meses quentes e que nos finais de semana consome-se mais bebidas, com consequente aumento no volume de garrafas e latas descartadas. A oscilação da temperatura também é importante porque, conforme reportagem publicada em 19 de dezembro de 2008 pela Revista Veja, baseada num estudo elaborado pela Empresa LCA Consultores, constatou-se que um incremento em $1 \%$ na temperatura corresponde a um aumento de $0,28 \%$ no consumo de bebidas. O descarte de papel e papelão não sofre influência da temperatura, mas sim com a época do ano, sendo maior no verão que nos meses de inverno. A Tabela 1 apresenta o re- sultado da estimativa de produção obtida por simulação de resíduos em parte dos 38 bairros da cidade estudados.

A idéia deste trabalho foi distribuir espacialmente a localização dos centros de coleta por toda a região de estudo, de modo a diminuir distâncias percorridas pelos coletadores de produtos recicláveis. Como com esta estratégia de localização de centros de coleta de mercadorias (CCs), cada subregião deve ter disponível apenas um $\mathrm{CC}$, cujo tamanho e composição deverá ser posteriormente definido. Fica evidenciada a possibilidade de fila, pois cada um dos CC poderá estar sobrecarregado em épocas de grande demanda, como o verão.

Para aplicação no modelo a distância entre os distritos foi considerada como a distância centro a centro, acrescida da distância média interna do distrito que, por sua vez, foi determinada em função da área e da forma que as áreas urbanizadas se distribuem nesta sub-região.

Como existem distritos que possuem alta taxa de produção de resíduos e/ou grande população, procura-se, propositadamente, privilegiá-los, ou seja, pretende-se dar maior atenção para as regiões onde a demanda por entregas é maior. A Tabela 2 apresenta parte da matriz distância entre os centros dos 38 bairros da cidade estudados.

\section{DESENVOLVIMENTO DO MODELO COMPUTACIONAL}

O critério para distribuição espacial tem como base o princípio de a soma das distâncias médias entre todos os usuários do sistema e as facilidades disponíveis deve ser a menor possível, sujeito às restrições já explicitadas no capítulo precedente.

Existem basicamente três métodos para resolver o problema:

1. O processo de enumeração exaustiva, que requer o cálculo da função objetivo para cada combinação possível de $p$ nos $n$ locais viáveis para implantação das facilidades. No entanto o número de combinações de $p$ em $n$ locais pode ser muito elevado e o método da enumeração exaustiva pode requerer um volume de cálculos excessivo. É evidente que o processo de busca exaustiva garante o melhor esquema de localização dos equipamentos, porém em sistemas com elevado número de distritos e várias unidades a distribuir, o número de combinações possíveis assume um valor tão elevado que o tempo de processamento se torna tão elevado que inviabiliza 


\begin{tabular}{|c|c|c|c|c|c|c|c|c|c|c|c|}
\hline Bairro & 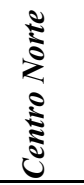 & 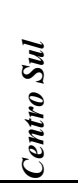 & 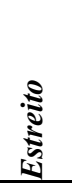 & 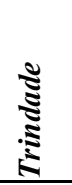 & 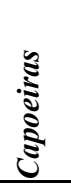 & ڤે & $\frac{\sqrt[5]{5}}{\sqrt[5]{5}}$ & $\begin{array}{l}\tilde{\Xi} \\
\vdots \\
5 \\
5 \\
0\end{array}$ & 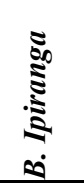 & 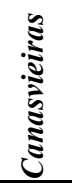 & 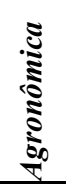 \\
\hline Centro Norte & 3,0 & 3,4 & 8,6 & 9,4 & 7,6 & 11,3 & 7,5 & 18,0 & 11,6 & 22,8 & 6,3 \\
\hline Centro Sul & 3,4 & 2,9 & 8,4 & 9,2 & 7,5 & 11,1 & 7,4 & 17,7 & 11,4 & 23,1 & 7,6 \\
\hline Estreito & 8,6 & 8,4 & 2,8 & 13,6 & 4,4 & 5,8 & 5,8 & 13,8 & 7,7 & 24,2 & 10,2 \\
\hline Trindade & 9,4 & 9,2 & 13,6 & 2,6 & 12,0 & 13,7 & 11,8 & 20,5 & 15,1 & 14,0 & 3,5 \\
\hline Capoeiras & 7,6 & 7,5 & 4,4 & 12,0 & 1,8 & 6,1 & 4,9 & 12,2 & 8,3 & 20,9 & 9,2 \\
\hline Barreiros & 11,3 & 11,1 & 5,8 & 13,7 & 6,1 & 3,0 & 6,6 & 12,1 & 4,7 & 27,3 & 13,7 \\
\hline Coqueiros & 7,5 & 7,4 & 5,8 & 11,8 & 4,9 & 6,6 & 3,0 & 12,6 & 7,6 & 20,7 & 9,1 \\
\hline Passa Vinte & 18,0 & 17,7 & 13,8 & 20,5 & 12,2 & 12,1 & 12,6 & 3,6 & 9,9 & 28,9 & 17,0 \\
\hline Bairro Ipiranga & 11,6 & 11,4 & 7,7 & 15,1 & 8,3 & 4,7 & 7,6 & 9,9 & 2,8 & 23,5 & 12,2 \\
\hline Canasvieiras & 22,8 & 23,1 & 24,2 & 14,0 & 20,9 & 27,3 & 20,7 & 28,9 & 23,5 & 2,3 & 14,0 \\
\hline Agronômica & 6,3 & 7,6 & 10,2 & 3,5 & 9,2 & 13,7 & 9,1 & 17,0 & 12,2 & 14,0 & 1,6 \\
\hline
\end{tabular}

Tabela 3. Resultado do modelo de alocação espacial

\begin{tabular}{|c|c|c|}
\hline$C C n^{o}$ & Localização & Distritos atendidos (área de influência) \\
\hline 1 & Centro Norte & $\begin{array}{l}\text { Centro Norte, Centro Sul Trindade, Agronômica, Itacorubi, Saco Grande, } \\
\text { Córrego Grande, Saco dos Limões, Costeira, Pantanal. }\end{array}$ \\
\hline 2 & Estreito & $\begin{array}{l}\text { Estreito, Barreiros, Bairro Bela Vista, Jardim Atlântico Capoeiras, Coqueiros, } \\
\text { Abraão, Itaguaçú. }\end{array}$ \\
\hline 3 & Campeche & $\begin{array}{l}\text { Campeche, Rio Tavares, Pântano do Sul, Armação, Ribeirão da Ilha Lagoa da Conceição, } \\
\text { Carianos, Tapera, Barra da Lagoa. }\end{array}$ \\
\hline 4 & Jurerê & $\begin{array}{l}\text { Jurerê, Daniela, Ratones, Canavieiras, Ingleses, Cacupé, Sambaqui, } \\
\text { Santo Antônio de Lisboa. }\end{array}$ \\
\hline 5 & Kobrasol I & $\begin{array}{l}\text { Kobrasol, Serraria, Biguaçú, Forquilhinhas, Campinas, São José, Roçado, Palhoça, } \\
\text { Passa Vinte, Praia de Fora, Paulo Lopes, Santo Amaro da Imperatriz, Aririú. }\end{array}$ \\
\hline
\end{tabular}

sua utilização;

2. Aproximações por programação matemática, que não estão prontamente disponíveis para problemas do tipo formulado neste trabalho, pois, se por um lado, a função objetivo é não linear, com desenvolvimento complicado em função das variáveis de decisão, por outro, o número de restrições e variáveis de decisão é muito grande, mesmo em problemas de tamanho moderado; e

3. Aproximações heurísticas. Uma que é mais facilmente aplicável no modelo que se pretende implementar neste trabalho é a proposta por Teitz e Bart in Reilly (1983), conhecido como "site-substituition approach". Essencialmente, este método inicia com um conjunto semente de pontos, estes são substituídos um a um, trocando-se os pontos dentro do conjunto corrente por pontos fora do conjunto corrente. Se a substituição de um determinado ponto viável para a instalação da facilidade reduz o valor da função objetivo, então o novo local é incluído e o local antigo é eliminado do conjunto corrente. Este processo continua até que nenhuma substituição conduza a um decréscimo de valor da função objetivo.

A Tabela 3 apresenta o resultado do modelo de alocação espacial dos centros de coleta na região da grande Florianópolis.

\section{CONCLUSÃO}

Conclui-se que a reciclagem é um conjunto de técnicas que tem por finalidade aproveitar os "detritos" e reutilizá-los no ciclo de produção de que saíram ou em um ciclo de produção paralelo. É uma atividade pela qual, materiais que poderiam se tornar lixo, ou que já estão no lixo, são desviados, coletados, separados e processados para serem usados como matéria-prima na manufatura de novos produtos. Como, para as empresas reclicadoras, estas matérias recuperadas sempre têm um custo mais conveniente que o da matéria prima original, cabe à logística para reciclagem viabilizar economicamente o transporte e a armazenagem dos produtos, obtendo, como efeito colateral benéfico, uma diminuição dos danos ambientais.

Aplicando-se a metodologia alocação espacial, com a região de estudo dividida em 38 sub-regiões, Chegou-se a conclusão que o sistema deveria dispor de, pelo menos quinze pequenos postos de coleta localizados nos principais bairros da cidade, nos quais os catadores entregariam os produtos recolhidos. Nestes postos deveria ser realizada uma primeira etapa de limpeza e triagem dos materiais. Posteriormente os produtos deveriam ser enviados para cinco centros de consolidação e armazenagem, localizados em prontos estratégicos, próximos de rodovias arteriais, onde sofreriam a triagem final e seriam compactados em fardos de tamanho conveniente para o despacho por caminhões com capacidade para movimentar até 15 toneladas.

Em média, a frequência de despacho dos caminhões para as indústrias recicladoras em cada um dos centros de consolidação varia conforme o material a ser transportado, sendo mais frequente para os papéis, um veículo a cada três dias, e menos frequente para os metais ferrosos, alumínio e vidros, um veículo a cada 10 dias.

Não foi feita uma análise financeira profunda, porém po- 
de-se inferir que, com a redução dos custos de deslocamento, o sistema provavelmente seria financeiramente viável. Com isto se garantiria uma remuneração justa para os proprietários dos postos de coleta e centros de consolidação e uma pequena renda para os catadores. Evidentemente, o ideal é que o valor recebido pelos catadores fosse incrementado, porém, como já foi citado, isto depende do preço que as indústrias se propõem a pagar pelos produtos recolhidos, que sempre é inferior ao preço das matérias primas de fontes convencionais.

\section{AGRADECIMENTOS}

Esta pesquisa foi financiada pelo Conselho Nacional de Desenvolvimento Científico e Tecnológico (CNPq), Projeto 520474/91-1 e 500031/02-9.

\section{REFERÊNCIAS BIBLIOGRÁFICAS}

CLM (1993) Reuse and recycling reverse logistics opportunities. Council of Logistics Management. Illinois.

Leite, R. (2003) Logística reversa: meio ambiente e competitividade. Prentice Hall, São Paulo.

Reilly, J. M., Development of a fire station placement model with consideration of multiple arriving units. Thesis (Ph.D.), Rensselaer Polytechnic Institute, New York (1983).

Rogers, S. e R. Tibben-Lembke (1998) Going backwards: reverse logistics trends and practices. Reverse Logistics Executive Council. Reno USA. 